\begin{tabular}{|c|l|}
\hline Title & Household income and the risk of incident hypertension in employees at multiple workplaces in Japan : J-HOPE \\
\hline Author(s) & Y anagiya, Shingo; Nakamura, Koshi; Ukawa, Shigekazu; T sutsumi, A kizumi; A tsumi, Tatsuya; Tamakoshi, A kiko \\
\hline Citation & $\begin{array}{l}\text { Hypertension Research, 43, 1445-1453 } \\
\text { https://doi.org/10.1038/s41440-020-0517-y }\end{array}$ \\
\hline Issue Date & $2020-12$ \\
\hline Doc URL & http://hdl.handle.net/2115/81664 \\
\hline Type & article (author version) \\
\hline File Information & Hypertens Res 24 A ugust 2020.pdf \\
\hline
\end{tabular}

Instructions for use 


\section{Household income and the risk of incident hypertension in employees at}

multiple workplaces in Japan: J-HOPE

Shingo Yanagiya ${ }^{1,2}$, Koshi Nakamura ${ }^{3,4}$, Shigekazu Ukawa ${ }^{3,5}$, Akizumi Tsutsumi ${ }^{6}$, Tatsuya Atsumi $^{7}$, Akiko Tamakoshi ${ }^{3}$

${ }^{1}$ Department of Public Health, Hokkaido University Graduate School of Medicine, Sapporo, Japan

${ }^{2}$ Department of Rheumatology, Endocrinology and Nephrology, Hokkaido University

Graduate School of Medicine, Sapporo, Japan

${ }^{3}$ Department of Public Health, Hokkaido University Faculty of Medicine, Sapporo, Japan

${ }^{4}$ Department of Public Health and Hygiene, University of the Ryukyus Graduate School of

Medicine, Nishihara, Okinawa, Japan

${ }^{5}$ Research Unit of Advanced Interdisciplinary Care Science, Osaka City University Graduate

School of Human Life Science, Osaka, Japan

${ }^{6}$ Department of Public Health, Kitasato University School of Medicine, Sagamihara, Japan

${ }^{7}$ Department of Rheumatology, Endocrinology and Nephrology, Hokkaido University Faculty of Medicine, Sapporo, Japan 
Address correspondence to: Koshi Nakamura, MD, PhD. Department of Public Health and Hygiene, University of the Ryukyus Graduate School of Medicine, 207 Uehara, Nishihara, Okinawa 903-0215, Japan $\quad$ Tel: +81-98-895-1136 Fax: +81-98-895-1412 E-mail: knakamur@med.u-ryukyu.ac.jp

Total word count: 4849 


\section{Abstract}

This cohort study aimed to investigate the association between household income and incident hypertension in employees in a Japanese employed population. During 2012, a total of 4314 normotensive daytime employees (3153 men and 1161 women) were included in this study. Participants had a wide range of occupations and were employed at one of 12 workplaces from various economic sectors in Japan. After a 2-year follow-up, incident hypertension was compared among groups according to household income: <5.0, 5.0-7.9, 8.0-9.9, and $\geq 10.0$ million Japanese yen (¥)/year. A Cox proportional hazard model was used to calculate the hazard ratio for incident hypertension in each household income group, compared with the group earning $<5.0$ million ¥/year. The hazard ratios for men were 1.52 (95\% confidence interval, 1.08-2.18) for 5.0-7.9 million ¥/year, 1.49 (0.98-2.27) for 8.0-9.9 million ¥/year, and 1.92 (1.23-3.01) for $\geq 10.0$ million ¥/year after adjusting for age, baseline systolic blood pressure, worksite, type of occupation, number of family members, and smoking status. This positive relationship was attenuated but remained significant after further adjustment for alcohol consumption and body mass index, both of which were higher among men with higher household income. Conversely, there was no significant difference for women in the risk of incident hypertension among household income groups, although those with higher household income tended to have a lower risk of incident hypertension. Household income is positively associated with the onset of hypertension in Japanese 
1 employed men working daytime hours.

2

3 Key words: epidemiology, household income, hypertension, Japan

4

5

6

7

8

9

10

11

12

13

14

15

16

17

18

19 


\section{Introduction}

Hypertension is a major risk factor for cardiovascular diseases including stroke and ischemic heart disease. ${ }^{1}$ Due to the relatively high prevalence of hypertension, there is an increased public burden resulting mainly from cardiovascular disease. ${ }^{2,3}$ It is well known that hypertension is associated with several lifestyle factors, including excessive intake of salt or alcohol, obesity, inactivity, and other personal attributes. ${ }^{4,5}$ Since socioeconomic status affects individual lifestyles and other factors, differences in socioeconomic status may influence the risk of hypertension. ${ }^{6}$ Therefore, it is important to clarify whether the risk of hypertension varies among socioeconomic classes when considering an effective strategy for preventing hypertension. Several previous epidemiological studies used household income as an index of socioeconomic status to investigate this topic. Hajat et al. ${ }^{7}$ observed a weak inverse relationship between wealth and incident hypertension among the civilian US population, whereas Leigh et al. ${ }^{8}$ reported that low income is a risk factor for hypertension among US employees. Cross-sectional studies in Canada and Poland observed an inverse association between household income and the presence of hypertension. ${ }^{9,10}$ Moreover, a cross-sectional study in Colombia reported a similar prevalence of hypertension among men across different household income levels. ${ }^{11}$ The same study also found a positive association between household income and hypertension among women, although a threshold effect of household 
1 income was seen. ${ }^{11}$ Even within Asian countries, this association is controversial. ${ }^{12-14}$ These

2 conflicting results from relevant studies may occur because economic conditions and cultural

3 backgrounds differ among countries. Evidence is scarce for Japan, which is more developed

4 than other Asian countries and may have different cultural backgrounds than other highly

5 developed countries, such as those in North America and Europe. Therefore, we investigated

6 the relationship between household income and incident hypertension in an employed

7 population in Japan.

8

9 Methods

10 Study design and population

The present cohort study was part of the Japanese study of Health, Occupation and

12 Psychosocial factors related Equity (J-HOPE) project. ${ }^{15,16}$ The overall goal of J-HOPE is to

13 develop and expand research to elucidate the mechanisms underlying the effects of social

14 differences on health and to establish measures to control these differences. The present

15 analysis was conducted with the J-HOPE dataset of December 12, 2016, which included

16 longitudinal data from 2012 to 2014. Written informed consent was obtained from each

17 participant. employed at one of 13 worksites participated in J-HOPE in 2012. As illustrated in Figure 1, of 
1 the original 14,189 participants, 1744 from one worksite were excluded because this location

2 failed to provide medical data. Of the remaining 12,445 participants at 12 worksites, 7463 met

3 one or more of the following exclusion criteria: (1) hypertension at baseline, defined as

4 systolic blood pressure (SBP) $\geq 140 \mathrm{mmHg}$, diastolic blood pressure (DBP) $\geq 90 \mathrm{mmHg}$,

5 and/or self-reported hypertension; ${ }^{17}$ (2) any type of workers other than daytime workers; and

6 (3) missing data on main variables and/or covariates at the time of the baseline survey. Since

7 rotating-shift workers are at a higher risk for hypertension than daytime workers, ${ }^{18}$ we

8 restricted the study participants to daytime workers. After these exclusions, 4982

9 normotensive participants were eligible for follow-up. We failed to obtain hypertension data

10 from 668 participants during the 2-year follow-up period. Therefore, only the remaining 4314

11 normotensive participants (3153 men and 1161 women) from 12 worksites were included in

12 the analyses.

\section{Baseline survey}

Annual household income was assessed using a self-administered questionnaire. The participants were asked to choose the most appropriate option of the following 6 income categories: $<3.0,3.0-4.9,5.0-7.9,8.0-9.9,10.0-14.9$, or $\geq 15.0$ million (MM) Japanese yen

$(¥) /$ year. Due to the small number of participants and hypertensive cases in the $<3.0$ and $\geq 15.0$ MM ¥/year groups, the following 4 yearly income groups were constructed for comparison: 
$1 \quad ¥(\$ 60.8-97.2 \mathrm{~K}) ; 8.0-9.9 \mathrm{MM} ¥(\$ 97.3-121.6 \mathrm{~K}) ;$ and $\geq 10.0 \mathrm{MM} ¥(\geq \$ 121.7 \mathrm{~K})$. The exchange

2 rate of $1000 ¥=\$ 12.17$ as of April 1, 2012, was used for this conversion.

A clinical examination was performed to measure resting blood pressure, height,

4 weight, glycated hemoglobin (HbA1c) level, and serum low-density lipoprotein cholesterol

5 level. All measurements were performed at the annual health checkup at the respective

6 worksites and followed a standard protocol. Using a standardized sphygmomanometer, blood

7 pressure was measured in the sitting position once on the right arm unless any specific

8 hindrance existed. Height and weight were measured, and body mass index (BMI) was

9 calculated as weight in kilograms divided by the square of height in meters $\left(\mathrm{kg} / \mathrm{m}^{2}\right)$. Fasting

10 blood samples were obtained, and the levels of HbA1c and serum low-density lipoprotein

11 cholesterol were measured using common methods. Data obtained via the questionnaire

12 included age, sex, medical history, worksite, type of occupation, number of family members,

13 and smoking status and alcohol consumption. Occupation types included the following 9

14 groups: managers, professionals, technicians, clerks, service and sales workers, craft and

15 related trade workers, machine operators, laborers, and others. The number of family

16 members including the participant was self-reported. Smoking status was classified according

17 to whether a participant had never smoked, had previously smoked, or was a current smoker.

18 Alcohol consumption was classified as being a nondrinker, occasional drinker, light daily

19 drinker ( $<46 \mathrm{~g}$ of alcohol per day), or heavy daily drinker ( $\geq 46 \mathrm{~g}$ of alcohol per day). The 
1 quantity of daily alcohol consumption was evaluated on the basis of $23 \mathrm{~g}$ of alcohol, which is

2 roughly equivalent to the following alcoholic beverages: $180 \mathrm{ml}$ (i.e., 1 “gou”) of sake

3 (Japanese rice wine), $500 \mathrm{ml}$ (one mid-sized bottle or one large can) of beer, or $60 \mathrm{ml}$ (one

4 double shot) of whisky. Diabetes was defined as HbA1c $\geq 6.5 \%$ and/or self-reported

5 diabetes, ${ }^{19}$ whereas hypercholesterolemia was defined as serum low-density lipoprotein

6 cholesterol $\geq 3.62 \mathrm{mmol} / 1$ (or $140 \mathrm{mg} / \mathrm{dl}$ ) and/or self-reported hypercholesterolemia. ${ }^{20}$

\section{$7 \quad$ Follow-up survey}

To identify incident cases of hypertension during the 2-year follow-up period, the

9 participants underwent annual health examinations until 2014. The procedures for measuring

10 blood pressure and obtaining the medical history were the same throughout the follow-up

11 period. The definition of hypertension was the same as that used for exclusion at baseline (i.e.,

$12 \mathrm{SBP} \geq 140 \mathrm{mmHg}, \mathrm{DBP} \geq 90 \mathrm{mmHg}$, or self-reported hypertension). ${ }^{17}$ If hypertension was

13 newly identified at the first or second annual follow-up survey, the time to event was counted

14 as 1 year or 2 years, respectively. In addition, household income was assessed again in the

15 year following the baseline year using the same questionnaire.

16 Statistical analysis

Analyses were conducted separately for men and women using anonymous data.

One-way analysis of variance, the Kruskal-Wallis test, or a chi-square test was used to 
1 the reported categories of household income, Spearman's correlation coefficient ( $\rho$ ) was

2 calculated between the baseline year and the next year by allocating scores of 1, 2, 3 and 4 for

3 all participants in the $<5.0,5.0-7.9,8.0-9.9$, and $\geq 10.0 \mathrm{MM}$ yen/year groups, respectively. The incidence of hypertension was compared among the 4 household income groups. Hazard ratios and 95\% confidence intervals for incident hypertension were calculated for each

6 income group, with the $<5.0 \mathrm{MM} ¥ /$ year group serving as a reference. A Cox proportional

7 hazards regression model was used, including age (years as a continuous variable), baseline

8 SBP (mmHg as a continuous variable), worksite, type of occupation (described above; 9

9 dummy variables with "managers" as the reference), number of family members (persons as a

10 continuous variable), and smoking status (described above; 3 dummy variables with "never a

11 smoker" as the reference) as potential confounding factors. Household income may have

12 determined lifestyle choices, some of which were risk factors for the development of

13 hypertension. We therefore assumed that such choices could be potential mediators of the

14 association between household income and incident hypertension. The model further incorporated the following covariates as potential mediators: alcohol consumption (described

16 above; 4 dummy variables with "nondrinker” as the reference) and BMI ( $\mathrm{kg} / \mathrm{m}^{2}$ as a continuous variable). The trend tests were performed by allocating scores of $1,2,3$, and 4 for all participants in each household income group in ascending order. 
1 household income with incident hypertension via a multivariate analysis that incorporated age

2 as a covariate. However, household income largely depends on age for employees in Japan,

3 and therefore, age may substantially confound the association of interest. It may be

4 insufficient to perform statistical analysis in a study population with a wide range of ages. To

5 further eliminate the confounding effect of age, the statistical analyses were repeated in the

6 study population stratified by age (18 to 34, 35 to 49, and 50 to 69 years).

The significance of the interaction between household income and sex was then

8 tested with regards to incident hypertension using an interaction term for the categorical

9 variables in the multivariate-adjusted models with and without the covariates of alcohol

10 consumption and BMI.

All analyses were performed using JMP Pro 14 software for Windows (SAS Institute

Inc., Cary, NC). All statistical analyses were two-tailed, with the significance level set at p <

0.05 .

This study was approved by the Ethics Review Boards of the University of Tokyo

15 Faculty of Medicine, Kitasato University School of Medicine/Hospital, and University of

16 Occupational and Environmental Health. The present analysis was also approved by the of Medicine. 


\section{Results}

\section{Characteristics of the study population}

The mean ( \pm standard deviation) participant age and BMI were $40.8 \pm 9.2$ years and $23.0 \pm 2.9 \mathrm{~kg} / \mathrm{m}^{2}$ for men and $38.3 \pm 9.8$ years and $20.9 \pm 3.0 \mathrm{~kg} / \mathrm{m}^{2}$ for women, respectively.

Tables 1 and 2 present the baseline characteristics of men and women, respectively, grouped according to household income at baseline. For both men and women, household income increased with age. Men, but not women, with higher household income had a higher prevalence of daily alcohol drinking and BMI $\geq 25 \mathrm{~kg} / \mathrm{m}^{2}$. The prevalence of managers increased among men with higher household income, whereas the likelihood of being a professional was highest in the $\geq 10 \mathrm{MM} ¥$ income bracket for women. The prevalence of diabetes increased for both men and women with higher household income, whereas those with the lowest household income had the lowest prevalence of hypercholesterolemia. In all participants ( $n=4207)$, excluding participants lacking data on household income in the next year survey ( $\mathrm{n}=107)$, there was a highly positive correlation between the baseline year and the next year with respect to the reported categories of household income $(\rho=0.77, \mathrm{P}<0.001)$.

\section{Household income and the risk of incident hypertension}

For men, household income was positively associated with the incidence of hypertension (Table 3). The hazard ratios for incident hypertension in men were 1.52 (95\% confidence interval, 1.08-2.18) for the 5.0-7.9 MM ¥/year group, 1.49 (0.98-2.27) for the 
8.0-9.9 MM ¥/year group, and 1.92 (1.23-3.01) for the $\geq 10.0 \mathrm{MM} ¥ /$ year group after

adjusting for age, baseline SBP, worksite, type of occupation, number of family members, and smoking status. These hazard ratios were slightly attenuated after additional adjustment for either alcohol consumption or BMI, both of which rose with increasing household income among men. The hazard ratios were further attenuated after adjustment for alcohol consumption and BMI in combination. The hazard ratio in the $\geq 10.0 \mathrm{MM} ¥ /$ year group was 1.79 (1.15-2.81) after the final adjustment. The trend of increasing hypertension risk with higher household income remained significant after all adjustments.

The positive association between household income and incident hypertension was shown in men aged 35 to 49 years (Table 3). As the group with the second highest household income was likely to have the highest hazard ratio among the 4 household income groups of men aged 18 to 34 years, a pattern similar to that observed in all men participating in the study was also likely to be applicable to this age stratum (Table 3). However, the hazard ratio was approximately 1 across household income groups of men aged 50 to 69 years (Table 3). For women, there was no significant difference in the risk of incident hypertension among the 4 household income groups; however, those with higher household income tended to have a lower risk of incident hypertension (Table 4). Age-stratified analyses could not be performed due to the small number of hypertensive cases in each household income group. The test of the interaction for incident hypertension between household income and 
1 sex almost showed significance in each multivariate-adjusted model $(\mathrm{P}=0.061$ for the model

2 without the alcohol consumption and $\mathrm{BMI}$ covariates and $\mathrm{P}=0.058$ for the model with these

3 two covariates).

4

5 Discussion

In our study, possible sex differences were found in the relationship between

household income and the incidence of hypertension in a Japanese employed population.

8 Household income was positively associated with the risk of incident hypertension in men

9 even after adjusting for potential confounding variables. This positive association between

10 income and incident hypertension was likely to be applicable to men aged 18 to 49 years, but

11 the relationship of interest was null in men aged 50 to 69 years. Conversely, our data indicate a likely inverse relationship between household income and the risk of incident hypertension in women. The relationships between household income and incident hypertension reported in

15 previous studies have been controversial, presumably due to the different social backgrounds

16 among the countries studied. Robert et al. ${ }^{21}$ reported that in the US, people with lower

17 incomes were more likely to believe that social and economic factors determine health. In this regard, people with fewer economic resources may feel frustration or shame when comparing

19 themselves to people with greater economic resources. ${ }^{22,23}$ Therefore, a low socioeconomic 
1 status may have an adverse influence on blood pressure through such negative psychosocial

2 aspects. ${ }^{24}$ Indeed, several studies observed an inverse association between household income

3 and incident hypertension in the general ${ }^{7}$ and employed ${ }^{8}$ population in the US. However, in

4 Japan, over $70 \%$ of those who have low household income equivalent to the lowest group

5 used in our study have homes. ${ }^{25}$ Furthermore, most Japanese people view themselves as

6 belonging to the middle socioeconomic class regardless of their actual socioeconomic status. ${ }^{26}$

7 Therefore, the definition of low income varies among countries, and this variation may

8 explain the discrepancies observed in the association between household income and incident

9 hypertension among countries, including developed nations.

Some Japanese surveys of household income and lifestyles reported that a higher

11 household income was associated with more undesirable lifestyles in men but not in women. ${ }^{27}$

12 These surveys support our results that men, but not women, with higher household income

13 had a higher prevalence of daily alcohol drinking and obesity, both of which are major risk

14 factors for hypertension. ${ }^{28,29}$ Furthermore, we found that this positive association was

15 attenuated but remained significant after further adjustment for BMI or alcohol consumption.

16 This result suggests that the presence of other underlying variables, such as long working

17 hours, may explain the positive association in men. Increased time at work (which usually represents hours in excess of scheduled hours) remains the industrial culture in Japan, especially among men. ${ }^{30,31}$ Working long hours modestly increases income among employees 
1 but also increases their risk of hypertension. ${ }^{32}$ In fact, our data confirmed that men with

2 higher household income had longer working hours. The proportions of men working $>40$

3 hours per week, which exceeds the work time limit based on the Labor Standards Act in

4 Japan, $^{33}$ were $51.0,68.5,72.3$, and $75.8 \%$ in the $<5.0,5.0-7.9,8.0-9.9$, and $\geq 10.0 \mathrm{MM} ¥ /$ year

5 groups, respectively (data not shown). The results of our age-stratified analyses suggest that

6 the positive association between household income and incident hypertension disappears

7 among employed men aged 50 or over. Unfortunately, in this study, we were unable to

8 determine the reason for the discrepancy in the relationship of interest among age strata.

We acknowledge several limitations in our study. First, the study participants

10 consisted solely of employed individuals working daytime hours, and therefore, the

11 association we observed may not be generally applicable to all employers, employees,

self-employed and unemployed persons. The national survey of Japanese household income

13 in 2012 shows that those having household incomes of <5.0 MM, 5.0-7.9 MM, 8.0-9.9 MM,

14 and $\geq 10.0 \mathrm{MM} ¥$ /year accounted for $57.3,22.3,8.8$, and $11.6 \%$ of the population,

15 respectively. ${ }^{34}$ However, in our study population, these respective proportions were 27.0, 41.0,

16 17.2, and 14.8\%. Although the populations of the two studies have equivalent middle-to-high

17 levels of household income, our study population did not accurately represent those having

18 low, especially extremely low, levels of household income. In our study, the lowest household

income group was defined as $<5.0 \mathrm{MM} ¥ /$ year. There is no clear definition of extremely low 
1 household income, but one possible criterion is under approximately 1.0-2.0 MM ¥/year, for

2 which tax exemption is applied. ${ }^{35}$ Men and women ( $\mathrm{n}=107$ and 667, respectively) earning

$3<3.0 \mathrm{MM} ¥ /$ year accounted for only $3.4 \%$ and $17.1 \%$ of our male and female populations,

4 respectively. Such a low prevalence of extremely low household income, especially in men,

5 may have been observed because our study population consisted only of employees who

6 regularly earned a salary. Thus, our study did not include data on individuals with extremely

7 low household income, which warrants caution when interpreting the results. Second, the data

8 on household income were collected via a self-administered questionnaire including 6 options

9 we originally developed and was therefore restricted for use in this analysis. Ideally, we

10 should have considered the number of household members to create a better index of

11 household income (e.g., household income divided by the square root of the number of

12 household members). ${ }^{36}$ Instead, we incorporated the number of family members in the

13 statistical model as a covariate. In addition to the highly positive correlation between the 2

14 years with respect to the reported categories of household income, a previous J-HOPE study

15 reported that a group with higher household income was older and better educated on average

16 and had a higher prevalence of managers than a group with lower household income. ${ }^{37}$ These

17 results support the validity and reliability of our questionnaire about household income. Third,

18 the number of female participants was smaller than that of male participants, and there were

19 few female hypertensive individuals in a higher household income group. Therefore, caution 
1 should be used in interpreting our results for women. Fourth, blood pressure measurements

2 may not have been strictly standardized across workplaces. Therefore, we adjusted for

3 worksite to minimize potential bias due to nonstandardized measurements of blood pressure.

4 Fifth, the follow-up period was only 2 years, which is short for the evaluation of incident

5 hypertension. Finally, no data were collected on diet (especially salt intake), the amount of

6 sleep, and family history of hypertension. In this regard, Yamashita et al. ${ }^{38}$ reported that

7 household income had no association with the urinary sodium-to-potassium ratio in a

8 Japanese population.

In conclusion, household income was positively related to incident hypertension in

10 Japanese men employed during the daytime but not women. This positive association may be

11 mediated by obesity and high alcohol intake. Further studies should elucidate the underlying

12 mechanism for the positive association we observed. 


\section{Conflict of Interest/Disclosures}

2 None declared.

5 Acknowledgment

The authors would like to thank all participants in J-HOPE.

\section{Sources of Funding}

We used panel data from an occupational cohort study on social class and health in

11 Japan (J-HOPE), which was supported by a Grant-in-Aid for Scientific Research (KAKENHI) on Innovative Areas (Research in a Proposed Research Area) 2009-2013 (No. 4102-21119001) from the Ministry of Education, Culture, Sports, Science and Technology,

14 Japan. The present study was financially supported by a Grant-in Aid for Scientific Research 


\section{References}

1) Singh GM, Danaei G, Farzadfar F, Stevens GA, Woodward M, Wormser D, et al. The age-specific quantitative effects of metabolic risk factors on cardiovascular diseases and diabetes: a pooled analysis. PLoS One. 2013; 8: e65174.

2) Global Burden of Metabolic Risk Factors for Chronic Diseases Collaboration.

Cardiovascular disease, chronic kidney disease, and diabetes mortality burden of

cardiometabolic risk factors from 1980 to 2010: a comparative risk assessment. Lancet

Diabetes Endocrinol. 2014; 2: 634-647.

3) Ikeda N, Inoue M, Iso H, Ikeda S, Satoh T, Noda M, et al. Adult mortality attributable to preventable risk factors for non-communicable diseases and injuries in Japan: a comparative risk assessment. PLoS Med. 2012; 9: e1001160.

4) Yang MH, Kang SY, Lee JA, Kim YS, Sung EJ, Lee KY, et al. The Effect of Lifestyle Changes on Blood Pressure Control among Hypertensive Patients. Korean J Fam Med. 2017; 38: 173-180 (erratum: J Fam Med. 2017; 38: 311-312).

5) Hashimoto T, Takase H, Okado T, Sugiura T, Yamashita S, Kimura G, et al. Significance of adjusting salt intake by body weight in the evaluation of dietary salt and blood pressure. $\mathrm{J}$ Am Soc Hypertens. 2016; 10: 647-655.

6) Leng B, Jin Y, Li G, Chen L, Jin N. Socioeconomic status and hypertension: a meta-analysis. J Hypertens. 2015; 33: 221-229. 
1 7) Hajat A, Kaufman JS, Rose KM, Siddiqi A, Thomas JC. Do the wealthy have a health

2 advantage? Cardiovascular disease risk factors and wealth. Soc Sci Med. 2010: 71:

$3 \quad 1935-1942$.

4 8) Leigh JP, Du J. Are low wages risk factors for hypertension? Eur J Public Health. 2012; 22:

$5 \quad 854-859$.

6 9) Lemstra M, Rogers M, Moraros J. Income and heart disease: Neglected risk factor. Can

$7 \quad$ Fam Physician. 2015; 61: 698-704.

8 10) Nadrowski P, Podolecka E, Pajak A, Dorynska A, Drygas W, Bielecki W, et al. How does

9 the risk of cardiovascular death and cardiovascular risk factor profiles differ between

10 socioeconomic classes in Poland: A country in transition. Cardiol J. 2019; 26: 493-502.

11 11) Lucumi DI, Schulz AJ, Roux AVD, Grogan-Kaylor A. Income inequality and high blood

12 pressure in Colombia: a multilevel analysis. Cad. Saude Publica. 2017; 33: e00172316.

13 12) Baek TH, Lee HY, Lim NK, Park HY. Gender differences in the association between

14 socioeconomic status and hypertension incidence: the Korean Genome and Epidemiology

15 Study (KoGES). BMC Public Health. 2015; 15: 852.

16 13) Sun $\mathrm{Z}$, Zheng L, Detrano $\mathrm{R}$, Zhang $\mathrm{X}, \mathrm{Xu} \mathrm{C}, \mathrm{Li} \mathrm{J}$, et al. Incidence and Predictors of

17 Hypertension Among Rural Chinese Adults: Results from Liaoning province. Ann Fam

18 Med. 2010; 8: 19-24.

19 14) Thawornchaisit P, de Looze F, Reid CM, Seubsman SA, Sleigh AC; Thai Cohort Study 
1 Team. Health risk factors and the incidence of hypertension: 4-year prospective findings

2 from a national cohort of 60569 Thai Open University students. BMJ Open. 2013; 3:

$3 \quad$ e002826.

4 15) Oshio $T$, Inoue $A$, Tsutsumi A. Examining the mediating effect of work-to-family 5 conflict on the associations between job stressors and employee

$6 \quad$ psychological distress: a prospective cohort study. BMJ Open. 2017; 7: e015608.

7 16) Oshio $T$, Tsutsumi $A$, Inoue $A$. Can leisure-time physical activity improve health 8 checkup results? Evidence from Japanese occupational panel data. J Occup $9 \quad$ Health. 2016; 58: 354-364.

17) Umemura S, Arima H, Arima S, Asayama K, Dohi Y, Hirooka Y, et al. The Japanese

11 Society of Hypertension Guidelines for the Management of Hypertension (JSH 2019). Hypertens Res. 2019; 42: 1235-1481.

18) Morikawa Y, Nakagawa H, Miura K, Ishizaki M, Tabata M, Nishijo M, et al. Relationship between shift work and onset of hypertension in a cohort of manual workers. Scand J Work Environ Health. 1999; 25: 100-104.

19) Haneda M, Noda M, Origasa H, Noto H, Yabe D, Fujita Y, et al. Japanese Clinical 17 Practice Guideline for Diabetes 2016. Diabetol Int. 2018; 9: 1-45 (erratum: Diabetol Int. 2018; 10: 83; Diabetol Int. 2019; 11: 163).

20) Kinoshita $M$, Yokote $\mathrm{K}$, Arai $\mathrm{H}$, Iida $\mathrm{M}$, Ishigaki $\mathrm{Y}$, Ishibashi $\mathrm{S}$, et al. Japan 
Atherosclerosis Society (JAS) Guidelines for Prevention of Atherosclerotic

2 Cardiovascular Diseases 2017. J Atheroscler Thromb. 2018; 25: 846-984.

21) Robert SA, Booske BC. US Opinions on Health Determinants and Social Policy as Health

$4 \quad$ Policy. Am J Public Health. 2011; 101: 1655-1663.

22) Wilkinson RG, Pickett KE. Income inequality and population health: a review and explanation of the evidence. Soc Sci Med. 2006; 62: 1768-1784.

23) Kawachi I, Kennedy BP. Income inequality and health: pathways and mechanisms. Health Serv Res. 1999; 34: 215-227.

24) Wilkinson RG. Socioeconomic determinants of health. Health inequalities: relative or absolute material standards? BMJ. 1997; 314: 591-595.

25) Statistics Bureau of Japan. Family Income and Expenditure Survey. https://www.e-stat.go.jp/stat-search/files?page=1\&layout=datalist\&toukei=00200561\&tstat $=000000330001 \&$ cycle $=7 \&$ year $=20170 \&$ month $=0 \&$ tclass $1=000000330001 \&$ tclass $2=0000$ 00330019\&tclass3 $=000000330020 \&$ result_back $=1 \quad$ (accessed 7 January 2020) [in Japanese].

26) Cabinet Office, Japan. The Public Opinion Survey on the Life of the People, 2016. https://survey.gov-online.go.jp/h28/h28-life/gairyaku.pdf (accessed 7 January 2020) [in Japanese].

27) Nakamura S, Inayama $T$, Hata $K$, Matsushita M, Takahashi M, Harada $K$, et al. 

Association of household income and education with eating behaviors in Japanese adults: a

2 cross-sectional study. BMC Public Health. 2016; 16: 61.

28) Wildman RP, Gu D, Muntner P, Huang G, Chen J, Duan X, et al. Alcohol intake and hypertension subtypes in Chinese men. J Hypertens. 2005; 23: 737-743.

29) Shihab HM, Meoni LA, Chu AY, Wang NY, Ford DE, Liang KY, et al. Body mass index and risk of incident hypertension over the life course: the Johns Hopkins Precursors Study. Circulation. 2012; 126: 2983-2989.

30) Iwasaki K, Takahashi M, Nakata A. Health problems due to long working hours in Japan: working hours, workers' compensation (Karoshi), and preventive measures. Ind Health. 2006; 44: 537-540.

31) The Japan Institute for Labour Policy and Training. Databook of International Labour http://www.jil.go.jp/kokunai/statistics/databook/2011/documents/databook2011.pdf (accessed 7 January 2020) [in Japanese; but tables are available in English].

32) Nakamura K, Sakurai M, Morikawa Y, Miura K, Ishizaki M, Kido T, et al. Overtime work and blood pressure in normotensive Japanese male workers. Am J Hypertens. 2012; 25: 979-985.

33) Ministry of Health, Labour and Welfare of Japan. Labour Standards Act. https://elaws.e-gov.go.jp/search/elawsSearch/elaws_search/lsg0500/detail?lawId=322AC00 
00000049 (accessed 7 January 2020) [in Japanese].

2 34) Ministry of Health, Labour and Welfare of Japan. Comprehensive Survey of Living

3 Conditions 2012. https://www.mhlw.go.jp/toukei/saikin/hw/k-tyosa/k-tyosa12/dl/03.pdf

$4 \quad$ (accessed 7 January 2020) [in Japanese].

5 35) Bureau of Taxation, Tokyo. Individual inhabitant tax

6 https://www.tax.metro.tokyo.jp/kazei/kojin_ju.html (accessed 7 January 2020) [in 7 Japanese]. (9)

36) Hoebel J, Kuntz B, Kroll LE, Schienkiewitz A, Finger LD, Lange C, et al. Socioeconomic Inequalities in the Rise of Adult Obesity: A Time-Trend Analysis of National Examination Data from Germany, 1990-2011. Obes Facts. 2019; 12: 344-356.

37) Miyaki K, Song Y, Taneichi S, Tsutsumi A, Hashimoto H, Kawakami N, et al. Socioeconomic status is significantly associated with the dietary intakes of folate and depression scales in Japanese workers (J-HOPE Study). Nutrients. 2013; 5: 565-578.

38) Yamashita M, Tabara Y, Higo Y, Setoh K, Kawaguchi T, Takahashi Y, et al. Association between socioeconomic factors and urinary sodium-to-potassium ratio: the Nagahama Study. Hypertens Res. 2018; 41: 973-980. 


\section{Figure Legends}

2 Figure 1. Flow chart for the inclusion of participants in the study. Hypertension was defined

3 as systolic blood pressure (SBP) $\geq 140 \mathrm{mmHg}$, diastolic blood pressure (DBP) $\geq 90 \mathrm{mmHg}$,

4 and/or self-reported hypertension. [Ref 17]

5 
Table 1. Baseline characteristics of the 3153 male participants grouped by household income.

\begin{tabular}{|c|c|c|c|c|c|}
\hline & \multicolumn{4}{|c|}{ Household income (million Japanese yen/year) [(thousand US dollars/year)] } & \multirow[b]{4}{*}{ P value } \\
\hline & $<5.0$ & $5.0-7.9$ & $8.0-9.9$ & $\geq 10.0$ & \\
\hline & {$[<60.8]$} & [60.8-97.2] & {$[97.3-121.5]$} & {$[\geq 121.7]$} & \\
\hline & $\mathrm{n}=667$ & $\mathrm{n}=1412$ & $\mathrm{n}=587$ & $\mathrm{n}=487$ & \\
\hline Age (years) & $33.0 \pm 10.1$ & $41.1 \pm 7.4$ & $45.1 \pm 7.0$ & $45.8 \pm 7.6$ & $<0.001$ \\
\hline Systolic blood pressure (mmHg) & $115.8 \pm 11.2$ & $116.5 \pm 11.1$ & $117.2 \pm 10.9$ & $118.8 \pm 10.9$ & $<0.001$ \\
\hline Diastolic blood pressure (mmHg) & $69.0 \pm 9.0$ & $72.2 \pm 8.8$ & $73.6 \pm 8.3$ & $74.3 \pm 8.4$ & $<0.001$ \\
\hline \multicolumn{6}{|l|}{ Type of occupation } \\
\hline Managers & 13 (1.9) & $163(11.5)$ & 255 (43.4) & 326 (66.9) & $<0.001$ \\
\hline Professionals & $123(18.4)$ & $258(18.3)$ & $94(16.0)$ & $43(8.8)$ & \\
\hline Technicians & 149 (22.3) & 304 (21.5) & $74(12.6)$ & $39(8.0)$ & \\
\hline Clerks & 89 (13.3) & $168(11.9)$ & $53(9.0)$ & $30(6.2)$ & \\
\hline Service and sales workers & $36(5.4)$ & $71(5.0)$ & 17 (2.9) & $5(1.0)$ & \\
\hline Craft and related trade workers & $72(10.8)$ & $133(9.4)$ & 38 (6.5) & $14(2.9)$ & \\
\hline Machine operators & $63(9.4)$ & $102(7.2)$ & $10(1.7)$ & $8(1.6)$ & \\
\hline Laborers & $59(8.8)$ & $72(5.1)$ & $16(2.7)$ & $2(0.4)$ & \\
\hline Others & $63(9.4)$ & $141(10.0)$ & $30(5.1)$ & $20(4.1)$ & \\
\hline Number of family members & $1(1-9)$ & $3(1-8)$ & $4(1-8)$ & $4(1-10)$ & $<0.001$ \\
\hline \multicolumn{6}{|l|}{ Smoking habit } \\
\hline Never & $383(57.4)$ & $721(51.1)$ & $302(51.4)$ & 236 (48.5) & $<0.001$ \\
\hline Ex-smoker & $59(8.8)$ & $206(14.6)$ & $89(15.2)$ & $94(19.3)$ & \\
\hline Current smoker & 225 (33.7) & 485 (34.3) & $196(33.4)$ & 157 (32.2) & \\
\hline \multicolumn{6}{|l|}{ Alcohol drinking habit } \\
\hline Non-drinker & 257 (38.5) & 436 (30.9) & 164 (27.9) & 95 (19.5) & $<0.001$ \\
\hline Occasional drinker & 263 (39.4) & $480(34.0)$ & 198 (33.7) & $182(37.4)$ & \\
\hline Light daily drinker & $98(14.7)$ & $280(19.8)$ & 145 (24.7) & $98(20.1)$ & \\
\hline Heavy daily drinker & 49 (7.3) & 216 (15.3) & $80(13.6)$ & $112(23.0)$ & \\
\hline \multicolumn{6}{|l|}{ Body mass index } \\
\hline$<25 \mathrm{~kg} / \mathrm{m}^{2}$ & $551(82.6)$ & $1102(78.0)$ & $465(79.2)$ & $342(70.2)$ & $<0.001$ \\
\hline$\geq 25 \mathrm{~kg} / \mathrm{m}^{2}$ & $116(17.4)$ & $310(22.0)$ & $122(20.8)$ & 145 (29.8) & \\
\hline Diabetes & $16(2.4)$ & $39(2.8)$ & $24(4.1)$ & $29(6.0)$ & 0.010 \\
\hline Hypercholesterolemia & $106(15.9)$ & $345(24.4)$ & $218(37.1)$ & 165 (33.9) & $<0.001$ \\
\hline
\end{tabular}

Values are presented as mean \pm standard deviation, median (minimum-maximum), or the number (\%) of participants in that category

One-way analysis of variance, Kruskal-Wallis test, or chi-square test was used to compare each characteristic in each household income group.

Light daily drinker was defined as consuming $<46$ g of alcohol per day, whereas heavy daily drinker was defined as consuming $\geq 46 \mathrm{~g}$ of alcohol per day. Diabetes was defined as HbA1c $\geq 6.5 \%$ and/or self-reported diabetes.[Ref 19]

Hypercholesterolemia was defined as serum low-density lipoprotein cholesterol $\geq 3.62 \mathrm{mmol} / \mathrm{l}$ and/or self-reported hypercholesterolemia.[Ref 20] 
Table 2. Baseline characteristics of the 1161 female participants grouped by household income.

\begin{tabular}{|c|c|c|c|c|c|}
\hline & \multicolumn{4}{|c|}{ Household income (million Japanese yen/year) [(thousand US dollars/year)] } & \multirow[b]{4}{*}{ P value } \\
\hline & $<5.0$ & $5.0-7.9$ & $8.0-9.9$ & $\geq 10.0$ & \\
\hline & {$[<60.8]$} & [60.8-97.2] & [97.3-121.5] & {$[\geq 121.7]$} & \\
\hline & $n=488$ & $\mathrm{n}=359$ & $\mathrm{n}=156$ & $\mathrm{n}=158$ & \\
\hline Age (years) & $35.8 \pm 10.6$ & $40.1 \pm 8.9$ & $40.2 \pm 8.9$ & $39.7 \pm 8.6$ & $<0.001$ \\
\hline Systolic blood pressure (mmHg) & $108.0 \pm 11.8$ & $109.3 \pm 12.5$ & $110.0 \pm 12.0$ & $109.1 \pm 10.6$ & 0.289 \\
\hline Diastolic blood pressure (mmHg) & $65.9 \pm 9.0$ & $66.9 \pm 9.7$ & $66.8 \pm 8.9$ & $66.5 \pm 9.3$ & 0.465 \\
\hline \multicolumn{6}{|l|}{ Type of occupation } \\
\hline Managers & $1(0.2)$ & $8(2.2)$ & $5(3.2)$ & $12(7.6)$ & $<0.001$ \\
\hline Professionals & $65(13.3)$ & $56(15.6)$ & $24(15.4)$ & $49(31.0)$ & \\
\hline Technicians & $27(5.5)$ & $17(4.7)$ & $5(3.2)$ & $6(3.8)$ & \\
\hline Clerks & 165 (33.8) & $116(32.3)$ & $56(35.9)$ & $56(35.4)$ & \\
\hline Service and sales workers & $9(1.8)$ & $4(1.1)$ & $1(0.6)$ & $1(0.6)$ & \\
\hline Craft and related trade workers & $15(3.1)$ & $10(2.8)$ & $2(1.3)$ & $3(1.9)$ & \\
\hline Machine operators & $20(4.1)$ & $21(5.9)$ & $5(3.2)$ & $2(1.3)$ & \\
\hline Laborers & $94(19.3)$ & $59(16.4)$ & $25(16.0)$ & $16(10.1)$ & \\
\hline Others & $92(18.9)$ & $68(18.9)$ & $33(21.2)$ & $13(8.2)$ & \\
\hline Number of family members & $2(1-9)$ & $3(1-8)$ & $3(1-7)$ & $3(1-8)$ & $<0.001$ \\
\hline \multicolumn{6}{|l|}{ Smoking habit } \\
\hline Never & $421(86.3)$ & $320(89.1)$ & $136(87.2)$ & 142 (89.9) & 0.098 \\
\hline Ex-smoker & $29(5.9)$ & $9(2.5)$ & $3(1.9)$ & $5(3.2)$ & \\
\hline Current smoker & $38(7.8)$ & $30(8.4)$ & $17(10.9)$ & $11(7.0)$ & \\
\hline \multicolumn{6}{|l|}{ Alcohol drinking habit } \\
\hline Non-drinker & 258 (52.9) & 205 (57.1) & $86(55.1)$ & $74(46.8)$ & 0.249 \\
\hline Occasional drinker & $181(37.1)$ & $112(31.2)$ & $46(29.5)$ & $63(39.9)$ & \\
\hline Light daily drinker & $36(7.4)$ & $35(9.7)$ & $19(12.2)$ & $17(10.8)$ & \\
\hline Heavy daily drinker & $13(2.7)$ & $7(2.0)$ & $5(3.2)$ & $4(2.5)$ & \\
\hline \multicolumn{6}{|l|}{ Body mass index } \\
\hline$<25 \mathrm{~kg} / \mathrm{m}^{2}$ & $454(93.0)$ & $324(90.3)$ & 139 (89.1) & $144(91.1)$ & 0.127 \\
\hline$\geq 25 \mathrm{~kg} / \mathrm{m}^{2}$ & $34(7.0)$ & $35(9.7)$ & 17 (10.9) & $14(8.9)$ & \\
\hline Diabetes & $4(0.8)$ & $3(0.8)$ & $3(1.9)$ & $4(2.5)$ & 0.287 \\
\hline Hypercholesterolemia & $55(11.3)$ & $70(19.5)$ & $29(18.6)$ & $21(13.3)$ & 0.014 \\
\hline
\end{tabular}

Values are presented as mean \pm standard deviation, median (minimum - maximum), or the number (\%) of participants in that category

One-way analysis of variance, Kruskal-Wallis test, or chi-square test was used to compare each characteristic in each household income group.

Light daily drinker was defined as consuming $<46 \mathrm{~g}$ of alcohol per day, whereas heavy daily drinker was defined as consuming $\geq 46 \mathrm{~g}$ of alcohol per day. Diabetes was defined as HbA1c $\geq 6.5 \%$ and/or self-reported diabetes.[Ref 19]

Hypercholesterolemia was defined as serum low-density lipoprotein cholesterol $\geq 3.62 \mathrm{mmol} / \mathrm{l}$ and/or self-reported hypercholesterolemia.[Ref 20] 
Table 3. Hazard ratios (95\% confidence intervals) for incident hypertension in male participants grouped by household income.

\begin{tabular}{|c|c|c|c|c|c|}
\hline & \multicolumn{4}{|c|}{ Household income (million Japanese yen/year) [(thousand US dollars/year)] } & \multirow{3}{*}{$\begin{array}{l}\mathrm{P} \text { value } \\
\text { for trend }\end{array}$} \\
\hline & $<5.0$ & $5.0-7.9$ & $8.0-9.9$ & $\geq 10.0$ & \\
\hline & {$[<60.8]$} & [60.8-97.2] & [97.3-121.5] & {$[\geq 121.7]$} & \\
\hline \multicolumn{6}{|l|}{ Overall } \\
\hline Participants & 667 & 1412 & 587 & 487 & \\
\hline Person-years of follow-up & 1217 & 2564 & 1044 & 839 & \\
\hline Cases of incident hypertension & 45 & 188 & 89 & 105 & \\
\hline Incidence rate (/1000 person-years) & 37.0 & 73.3 & 85.2 & 125.1 & \\
\hline Hazard ratio, model 1 & 1.00 (reference) & $1.41(1.02-2.00)$ & $1.35(0.92-1.98)$ & $1.62(1.10-2.39)$ & 0.048 \\
\hline Hazard ratio, model 2 & 1.00 (reference) & $1.52(1.08-2.18)$ & $1.49(0.98-2.27)$ & $1.92(1.23-3.01)$ & 0.016 \\
\hline Hazard ratio, model 3 & 1.00 (reference) & $1.49(1.06-2.13)$ & $1.46(0.96-2.22)$ & $1.85(1.18-2.90)$ & 0.024 \\
\hline Hazard ratio, model 4 & 1.00 (reference) & $1.48(1.06-2.12)$ & $1.48(0.97-2.24)$ & $1.85(1.19-2.90)$ & 0.021 \\
\hline Hazard ratio, model 5 & 1.00 (reference) & $1.45(1.03-2.07)$ & $1.44(0.95-2.19)$ & $1.79(1.15-2.81)$ & 0.029 \\
\hline \multicolumn{6}{|l|}{ 18-34 years old } \\
\hline Participants & 437 & 261 & 42 & 45 & \\
\hline Person-years of follow-up & 808 & 463 & 70 & 80 & \\
\hline Cases of incident hypertension & 21 & 27 & 5 & 6 & \\
\hline Incidence rate (/1000 person-years) & 26.0 & 58.3 & 71.4 & 75.0 & \\
\hline Hazard ratio, model 1 & 1.00 (reference) & $1.45(0.71-2.98)$ & $1.57(0.47-4.45)$ & $1.29(0.43-3.33)$ & 0.768 \\
\hline Hazard ratio, model 2 & 1.00 (reference) & $1.47(0.70-3.15)$ & $1.81(0.50-5.86)$ & $1.25(0.36-3.88)$ & 0.716 \\
\hline Hazard ratio, model 3 & 1.00 (reference) & $1.45(0.69-3.09)$ & $1.87(0.51-6.10)$ & $1.31(0.38-4.10)$ & 0.726 \\
\hline Hazard ratio, model 4 & 1.00 (reference) & $1.44(0.68-3.11)$ & $1.97(0.53-6.45)$ & $1.20(0.35-3.77)$ & 0.681 \\
\hline Hazard ratio, model 5 & 1.00 (reference) & $1.43(0.67-3.07)$ & $2.18(0.59-7.28)$ & $1.26(0.36-3.98)$ & 0.628 \\
\hline \multicolumn{6}{|l|}{ 35-49 years old } \\
\hline Participants & 175 & 972 & 397 & 278 & \\
\hline Person-years of follow-up & 327 & 1787 & 726 & 474 & \\
\hline Cases of incident hypertension & 13 & 123 & 52 & 62 & \\
\hline Incidence rate (/1000 person-years) & 39.8 & 68.8 & 71.6 & 130.8 & \\
\hline Hazard ratio, model 1 & 1.00 (reference) & $1.49(0.86-2.80)$ & $1.37(0.74-2.69)$ & $2.01(1.08-3.99)$ & 0.094 \\
\hline Hazard ratio, model 2 & 1.00 (reference) & $1.69(0.96-3.22)$ & $1.57(0.81-3.22)$ & $2.49(1.23-5.30)$ & 0.039 \\
\hline Hazard ratio, model 3 & 1.00 (reference) & $1.60(0.91-3.06)$ & $1.51(0.78-3.11)$ & $2.34(1.16-4.99)$ & 0.064 \\
\hline Hazard ratio, model 4 & 1.00 (reference) & $1.75(0.99-3.33)$ & $1.63(0.84-3.34)$ & $2.53(1.25-5.40)$ & 0.042 \\
\hline Hazard ratio, model 5 & 1.00 (reference) & $1.64(0.93-3.14)$ & $1.55(0.80-3.19)$ & $2.36(1.16-5.04)$ & 0.070 \\
\hline \multicolumn{6}{|l|}{ 50-69 years old } \\
\hline Participants & 55 & 179 & 148 & 164 & \\
\hline Person-years of follow-up & 82 & 314 & 248 & 285 & \\
\hline Cases of incident hypertension & 11 & 38 & 32 & 37 & \\
\hline Incidence rate (/1000 person-years) & 134.1 & 121.0 & 129.0 & 129.8 & \\
\hline Hazard ratio, model 1 & 1.00 (reference) & $0.89(0.43-1.97)$ & $0.90(0.41-2.07)$ & $0.84(0.39-1.92)$ & 0.977 \\
\hline Hazard ratio, model 2 & 1.00 (reference) & $0.84(0.39-1.91)$ & $0.95(0.42-2.28)$ & $1.01(0.42-2.55)$ & 0.915 \\
\hline Hazard ratio, model 3 & 1.00 (reference) & $0.86(0.40-1.94)$ & $0.99(0.44-2.39)$ & $1.02(0.42-2.61)$ & 0.917 \\
\hline Hazard ratio, model 4 & 1.00 (reference) & $0.82(0.38-1.85)$ & $0.93(0.41-2.20)$ & $0.95(0.40-2.39)$ & 0.917 \\
\hline Hazard ratio, model 5 & 1.00 (reference) & $0.84(0.39-1.91)$ & $0.99(0.44-2.37)$ & $0.99(0.41-2.52)$ & 0.911 \\
\hline
\end{tabular}

Five different Cox proportional

Model 1, adjusted for age, baseline systolic blood pressure, and worksite.

Model 2, adjusted for covariates included in model 1 + number of family members, smoking habit, and type of occupation.

Model 3, adjusted for covariates included in model $2+$ alcohol drinking habit.

Model 4, adjusted for covariates included in model $2+$ body mass index.

Model 5, adjusted for covariates included in model $2+$ alcohol drinking habit and body mass index.

Hypertension was defined as systolic blood pressure $\geq 140 \mathrm{mmHg}$, diastolic blood pressure $\geq 90 \mathrm{mmHg}$ and/or self-reported hypertension.[Ref 17] 
Table 4. Hazard ratios (95\% confidence intervals) for incident hypertension in female participants grouped by household income.

\begin{tabular}{|c|c|c|c|c|c|}
\hline & \multicolumn{4}{|c|}{ Household income (million Japanese yen/year) [(thousand US dollars/year)] } & \multirow{3}{*}{$\begin{array}{l}\mathrm{P} \text { value } \\
\text { for trend }\end{array}$} \\
\hline & $<5.0$ & $5.0-7.9$ & 8.0-9.9 & $\geq 10.0$ & \\
\hline & {$[<60.8]$} & [60.8-97.2] & {$[97.3-121.5]$} & {$[\geq 121.7]$} & \\
\hline \multicolumn{6}{|l|}{$\overline{\text { Overall }}$} \\
\hline Participants & 488 & 359 & 156 & 158 & \\
\hline Person-years of follow-up & 897 & 659 & 292 & 282 & \\
\hline Cases of incident hypertension & 24 & 24 & 10 & 7 & \\
\hline Incidence rate (/1000 person-years) & 26.8 & 36.4 & 34.2 & 24.8 & \\
\hline Hazard ratio, model 1 & 1.00 (reference) & $1.00(0.55-1.82)$ & $0.81(0.36-1.71)$ & $0.67(0.25-1.60)$ & 0.350 \\
\hline Hazard ratio, model 2 & 1.00 (reference) & $1.05(0.57-1.94)$ & $0.78(0.33-1.71)$ & $0.65(0.22-1.72)$ & 0.372 \\
\hline Hazard ratio, model 3 & 1.00 (reference) & $1.06(0.58-1.96)$ & $0.78(0.33-1.71)$ & $0.66(0.22-1.74)$ & 0.379 \\
\hline Hazard ratio, model 4 & 1.00 (reference) & $0.98(0.53-1.82)$ & $0.75(0.32-1.66)$ & $0.57(0.20-1.51)$ & 0.258 \\
\hline Hazard ratio, model 5 & 1.00 (reference) & $0.99(0.53-1.83)$ & $0.74(0.31-1.65)$ & $0.58(0.20-1.54)$ & 0.267 \\
\hline
\end{tabular}

Five different Cox proportional hazards regression models were used as follows:

Model 1, adjusted for age, baseline systolic blood pressure, and worksite.

Model 2, adjusted for covariates included in model $1+$ number of family members, smoking habit, and type of occupation.

Model 3, adjusted for covariates included in model $2+$ alcohol drinking habit.

Model 4, adjusted for covariates included in model $2+$ body mass index.

Model 5, adjusted for covariates included in model $2+$ alcohol drinking habit and body mass index.

Hypertension was defined as systolic blood pressure $\geq 140 \mathrm{mmHg}$, diastolic blood pressure $\geq 90 \mathrm{mmHg}$ and/or self-reported hypertension.[Ref 17] 


\section{Participants in J-HOPE, $\mathrm{n}=14189$ (response rate 97.6\%)}

Exclusions:

- Medical checkup data not provided at 1 worksite $(n=1744)$

Participants at 12 worksites, $\mathrm{n}=12445$

Exclusions:

- Hypertension existed at baseline $(n=2090)$

- Workers not on daytime hours $(n=4561)$

- Missing data on household income $(n=43)$;

SBP, DBP or self-reported hypertension status $(n=706)$;

and other items used as covariates $(n=63)$

Participants eligible for follow-up, $n=4982$

Exclusions:

.... - Failure to obtain data on SBP, DBP or

self-reported hypertension status at follow-up survey $(n=668)$

Participants included for analysis, $\mathrm{n}=4314$ (3153 men and 1161 women) 